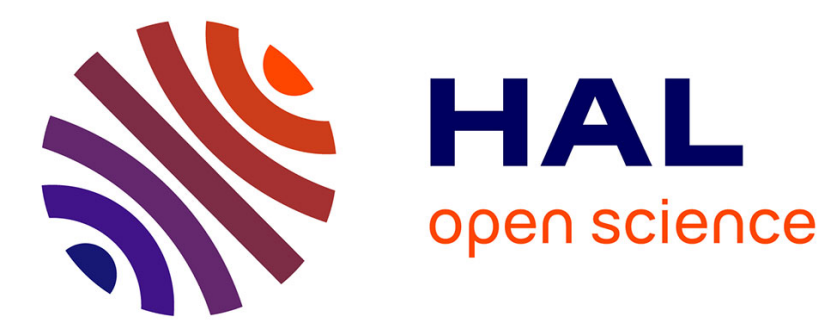

\title{
A multifaceted assessment of the effects of polyethylene microplastics on juvenile gilthead seabreams (Sparus aurata)
}

Hugo Jacob, Marc Besson, François Oberhaensli, Angus Taylor, Benjamin Gillet, Sandrine Hughes, Steven Melvin, Paco Bustamante, Peter Swarzenski, David Lecchini, et al.

\section{To cite this version:}

Hugo Jacob, Marc Besson, François Oberhaensli, Angus Taylor, Benjamin Gillet, et al.. A multifaceted assessment of the effects of polyethylene microplastics on juvenile gilthead seabreams (Sparus aurata). Aquatic Toxicology, 2021, 241, pp.106004. 10.1016/j.aquatox.2021.106004 . hal-03490610

\section{HAL Id: hal-03490610 https://hal.science/hal-03490610}

Submitted on 13 Jan 2022

HAL is a multi-disciplinary open access archive for the deposit and dissemination of scientific research documents, whether they are published or not. The documents may come from teaching and research institutions in France or abroad, or from public or private research centers.
L'archive ouverte pluridisciplinaire HAL, est destinée au dépôt et à la diffusion de documents scientifiques de niveau recherche, publiés ou non, émanant des établissements d'enseignement et de recherche français ou étrangers, des laboratoires publics ou privés. 


\section{A multifaceted assessment of the effects of polyethylene microplastics on juvenile gilthead}

seabreams (Sparus aurata)

Hugo Jacob ${ }^{1, \#}$, Marc Besson ${ }^{2, \#, ~ F r a n c ̧ o i s ~ O b e r h a e n s l i ~}{ }^{3}$, Angus Taylor ${ }^{3}$, Benjamin Gillet ${ }^{4}$, Sandrine Hughes ${ }^{4}$, Steven D Melvin ${ }^{5}$, Paco Bustamante ${ }^{6,7}$, Peter W. Swarzenski ${ }^{3}$, David Lecchini $^{1,8}$, Marc Metian ${ }^{3}$

1 PSL Research University: EPHE-UPVD-CNRS, USR 3278 CRIOBE BP 1013, 98729 Papetoai, Moorea, French Polynesia

2 School of Biological Sciences, University of Bristol, UK

3. International Atomic Energy Agency - Environment Laboratories, 4a Quai Antoine 1er, MC-98000, Principality of Monaco, Monaco

$4 \quad$ Institut de Génomique Fonctionnelle de Lyon, Université de Lyon, Université Claude Bernard Lyon 1, UMR CNRS 5242, Ecole Normale Supérieure de Lyon, Lyon, France

5 Australian Rivers Institute, Griffith University Gold Coast, Building G51, Edmund Rice Drive, Southport, Q4215, Australia

6 Littoral Environnement et Sociétés (LIENSs), UMR 7266 CNRS-La Rochelle Université, 2 rue Olympe de Gouges, 17000 La Rochelle, France

7 Institut Universitaire de France (IUF), 1 rue Descartes 75005 Paris, France

8 Laboratoire d'Excellence "CORAIL", 98729 Papetoai, Moorea, French Polynesia

\# Equal contributions

Corresponding author: Dr. Marc Metian / m.metian@iaea.org 


\begin{abstract}
Plastic pollution has become a major environmental and societal concern in the last decade. From larger debris to microplastics (MP), this pollution is ubiquitous and particularly affects aquatic ecosystems. MP can be directly or inadvertently ingested by organisms, transferred along the trophic chain, and sometimes translocated into tissues. However, the impacts of such MP exposure on organisms' biological functions are yet to be fully understood. Here, we used a multi-diagnostic approach at multiple levels of biological organization (from atoms to organisms) to determine how MP affect the biology of a marine fish, the gilthead seabream, Sparus aurata. We exposed juvenile seabreams for 35 days to spherical $10-20 \mu$ m polyethylene primary MP through food (Artemia salina pre-exposed to MP) at a concentration of $5 \pm 1 \mu \mathrm{g}$ of MP per gram of fish per day. MP-exposed fish experienced higher mortality, increased abundance of several brain and liver primary metabolites, hepatic and intestinal histological defects, higher assimilation of an essential element $(\mathrm{Zn})$, and lower assimilation of a nonessential element $(\mathrm{Ag})$. In contrast, growth and muscle $\mathrm{C} / \mathrm{N}$ isotopic profiles were similar between control and MP-exposed fish, while variable patterns were observed for the intestinal microbiome. This comprehensive analysis of biological responses to MP exposure reveals how MP ingestion can cause negligible to profound effects in a fish species and contributes towards a better understanding of the causal mechanisms of its toxicity.
\end{abstract}

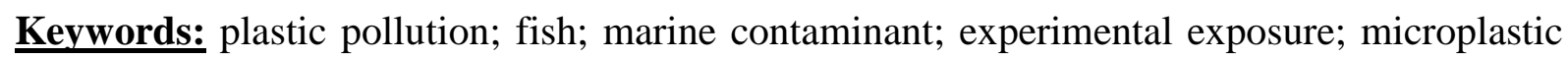
ingestion 


\section{Introduction}

An estimated 4 to 12 million tonnes of plastic debris enter the marine environments each year (Jambeck et al., 2015), thus polluting virtually all marine ecosystems, from ocean gyres (Eriksen et al., 2014) and coastal areas (Ling et al., 2017) to polar regions (Bergmann et al., 2017; Lusher et al., 2015) and deep sea sediment (Chiba et al., 2018). Among this pollution, plastic debris smaller than $5 \mathrm{~mm}$, or microplastics (MP) (Moore, 2008), are today considered a major environmental threat to marine organisms (Avio et al., 2017). MP can be manufactured products such as those used as additives in cosmetics and other personal care products, or may arise through the degradation of larger plastic debris by UV-radiation, mechanical abrasion, and biological degradation (Rochman, 2018; Ter Halle et al., 2016). Given their ubiquitous nature and small dimensions, MP may be ingested by aquatic organisms and subsequently transferred along the trophic chain, and in some cases have been shown to be translocated between internal tissues, the hazards of which are yet to be fully understood (Chae and An, 2017; Franzellitti et al., 2019).

To elucidate the hazards and potential toxicity associated with MP contamination, an exponentially growing number of in situ and laboratory studies have recently investigated the effects of MP on the biological functions of a variety of aquatic organisms (Franzellitti et al., 2019). Fish appear to be particularly susceptible to MP and have been so far the most studied aquatic organisms. MP have been found to alter multiple fish biological functions across various biological levels of organization (Jacob et al., 2020), such as behavioral anomalies and neurotoxicity (Choi et al., 2018; Yin et al., 2018), microbiome dysbiosis (Jin et al., 2018; Wan et al., 2019), oxidative stress (Barboza et al., 2018b, 2018a; Wan et al., 2019), impairments of the digestive system (Jabeen et al., 2018; Pedà et al., 2016; Romano et al., 2018) and altered metabolism (LeMoine et al., 2018; Wan et al., 2019). 
Studies investigating MP toxicity to fish have used a variety of exposure concentrations, fish species, particle shapes, sizes and types, as well as exposure route (e.g. water and food), and have examined dozens of biological markers (Jacob et al., 2020). However, this variety of parameters has rarely been investigated concomitantly within the same experimental framework, limiting our understanding of the linkages between the different effects of MP exposure on fish (Jacob et al., 2020). This is particularly true in the gilthead seabream (Sparus aurata) - a keystone species in the Mediterranean Sea and an important demersal commercial species, which biology and physiology have been extensively studied - for which recent research examining the effect of MP ingestion showed contrasting results on fish growth, isotopic signatures, and histological damage (Alomar et al., 2021; Vàro et al., 2021). Elucidating the causal mechanisms of MP toxicity to fish would therefore benefit from research that examines wider ranges of biological markers.

We performed a multi-diagnostic evaluation of the effects of MP on fish spanning different biological processes and multiple levels of organization. We exposed $S$. aurata juveniles to spherical 10-20 $\mu \mathrm{m}$ polyethylene primary MP through live food (Artemia salina) and examined a variety of biological, physiological, and histological markers in order to offer a uniquely broad evaluation of the impact of MP in a fish species, highlighting a wide range of biological effects and opening up hypotheses on the causal mechanisms underlying these effects. 


\section{Material and Methods}

\subsection{Fish acclimation}

A total of 200 gilthead seabream juveniles Sparus aurata (average wet weight $=3 \pm 0.5 \mathrm{~g}$, mean \pm SD) supplied by Les Poissons du Soleil (Balaruc-les-Bains, France) were acclimated at the IAEA-Environment Laboratories (Monaco) in a $500 \mathrm{~L}$ aquarium for 4 weeks prior to the MP exposure experiment. The aquarium was constantly aerated, in open-circuit, with water exchange rate at $80 \mathrm{~L} \mathrm{~h}^{-1}$, salinity at 38 , temperature at $17 \pm 0.1^{\circ} \mathrm{C}$, $\mathrm{pH}$ at $8.0 \pm 0.1$, and a 12 $\mathrm{h} / 12 \mathrm{~h}$ light/dark cycle was applied. During this acclimation period, the fish were fed a daily ration of $3 \%$ of their biomass with $1.1 \mathrm{~mm}$ pellets (Le Gouessant, France).

\subsection{Diet preparation}

Live adult brine shrimp (Artemia salina) were purchased from Grebil (Arry, France). Green fluorescent spherical polyethylene primary MP $(10-20 \mu \mathrm{m}, \mathrm{d}=1.025)$, in dry powder form, were purchased from Cospheric (USA). Two diets were prepared: a control diet and a MP diet. For the control diet, we prepared $5 \mathrm{~L}$ glass beakers, each filled with $2.5 \mathrm{~L}$ seawater $\left(\right.$ at $\left.17{ }^{\circ} \mathrm{C}\right)$

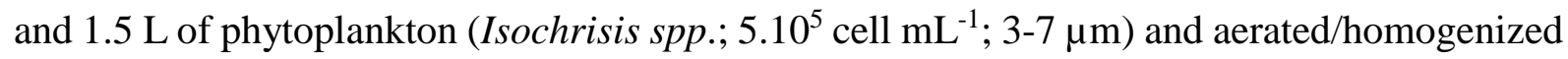
with 3 air stones connected to one air pump. For the MP diet, we applied the same procedure but then added $20 \mathrm{mg}$ of the MP particles described above to reach a concentration of $5 \mathrm{mg} \mathrm{L}^{-}$

${ }^{1}$. After $5 \mathrm{~min}$ of homogenization, $30 \mathrm{~g}$ wet weight (wwt) of alive brine shrimps were added to each beaker for both diets. Brine shrimps were then left for $3 \mathrm{~h}$ before being filtered in a small mesh hand-net and rinsed 3 times with $500 \mathrm{~mL}$ seawater to remove potential non-ingested MP (each beaker was filtered separately). We confirmed that all non-ingested MP were removed by this rinsing and that no MP were present on their body external parts by visually inspecting a small subset of brine shrimp using an inverted stereo microscope equipped with fluorescence light (Olympus, Ix73). For each diet, portions of $2.5 \mathrm{~g}$ (wwt) were prepared and placed in a 
freezer $\left(-20^{\circ} \mathrm{C}\right)$ until use. The protocol of Rist et al. (2017) was used to quantify the amount of MP ingested by brine shrimps in the MP diet. Seven subsamples of $0.1 \mathrm{~g}$ ( $22 \pm 2$ brine shrimps per subsample) from different batches (i.e. beaker preparations) were digested. Quantification of MP was done visually under an inverted stereo microscope equipped with fluorescence light (Olympus, Ix73). A count of $115631 \pm 24179$ MP per gram of brine shrimp was observed, corresponding to $522 \pm 86 \mathrm{MP}$ per brine shrimp (Tab. S1). The estimated dose provided to the fish was thus $87 \pm 18 \mu \mathrm{g}$ per fish per day or $48180 \pm 10074 \mathrm{MP}$ per fish per day (equivalent to $5 \pm 1 \mu \mathrm{g}$ or $2800 \pm 840 \mathrm{MP}$ per gram of fish per day).

\subsection{Fish exposure}

Two weeks before the exposure to the control or MP diets, 72 fish were randomly placed in six $20 \mathrm{~L}$ aquaria ( $\mathrm{n}=12$ fish per aquaria). Each aquarium was constantly aerated, in an open-circuit (water exchange rate set at $150 \mathrm{~L} \mathrm{~h}^{-1}$ ) receiving the same water source as during the first acclimation (see 2.1.). The average fish mass in the 6 aquaria was $9.0 \pm 0.8,9.0 \pm 0.9,9.0 \pm 1$, $8.8 \pm 0.8,8.8 \pm 0.8$, and $9.0 \pm 0.9 \mathrm{~g} w w t$, for a total biomass per aquaria ranging between 105.48 and $108.26 \mathrm{~g}$ wwt (i.e. fish density of $\sim 5.3 \mathrm{~kg} \mathrm{~m}^{-3}$ ). Each aquarium was then randomly assigned to receive either the control or MP diet, with 3 aquaria per treatment. The first feeding started on the $2^{\text {nd }}$ of July 2018 and the experiment lasted for 35 days. In each aquarium, fish were initially fed twice a day with $2.5 \mathrm{~g}$ wwt of the frozen brine shrimp diet (see 2.2), a daily feeding ration therefore corresponding to $5 \pm 0.46 \%$ of fish body weight per day. Fish were weighted after 14 days of exposure, and, as mortality occurred, the feeding ration was regularly adjusted to remain at $5 \pm 1 \%$ body weight per day. 


\subsection{Fish weight and survival}

Fish weight was assessed at the beginning of the experiment (D0), after 14 days of exposure (D14) and at the end of the exposure period (D35). Mortality was assessed daily in each aquarium, permitting the calculation of daily survival curves for each diet group.

\subsection{Fish sampling for subsequent analyses or experiments}

At the end of the exposure, 10 fish from each diet group were haphazardly selected and were transferred to 4 other aquaria (5 fish per aquarium, 2 aquaria per condition) to assess $\mathrm{Ag}$ and $\mathrm{Zn}$ assimilation and depuration kinetics (see subsection 2.10.). All other fish ( $\mathrm{n}=28$ for the control diet group and $n=14$ for the MP diet group) were euthanized and dissected for subsequent analyses (see subsections 2.6. to 2.9.).

\subsection{Carbon and Nitrogen isotopic ratios}

Muscle samples from $n=13$ control fish and $n=13$ MP-exposed fish were freeze-dried and grounded. As lipids are highly depleted in ${ }^{13} \mathrm{C}$ with regards to other tissue components due to fractionation occurring during lipid synthesis (DeNiro \& Epstein, 1977), isotopic analyses were performed on lipid-extracted samples. Lipid extraction was performed using cyclohexane on powder aliquots as previously described (Chouvelon et al., 2011). Aliquots of $0.30 \pm 0.10 \mathrm{mg}$ of lipid-free powder were weighed in tin cups for stable isotope analyses. These analyses were performed with a continuous flow mass spectrometer (Thermo Scientific Delta V Advantage) coupled to an elemental analyzer (Thermo Scientific Flash EA 1112). The results are presented in the usual $\delta$ notation relative to the deviation from standards (Pee Dee Belemnite for $\delta^{13} \mathrm{C}$ and atmospheric nitrogen for $\delta^{15} \mathrm{~N}$ ), in parts per thousand (\%o) following the formula:

$$
\delta^{13} C \text { or } \delta^{15} N=\left(\frac{R_{\text {sample }}}{R_{\text {standard }}}-1\right) \times 10^{3}
$$

where $\mathrm{R}$ is $\delta^{13} \mathrm{C}$ or $\delta^{15} \mathrm{~N}$, respectively. 
Based on replicate measurements of internal laboratory standards the experimental precision was $<0.15 \%$ for both $\delta^{13} \mathrm{C}$ and $\delta^{15} \mathrm{~N}$.

\subsection{Metabolomic analyses}

Livers, muscles and brains from $n=14$ control fish and $n=13$ MP-exposed fish were analyzed using Nuclear Magnetic Resonance (NMR) spectroscopy to explore how MP exposure influences basic metabolism. Samples were placed in Eppendorf tubes and immediately flashfrozen in liquid nitrogen and stored at $-80{ }^{\circ} \mathrm{C}$ until processing. Samples were then lyophilized and coarsely ground with a ceramic pestle prior to extraction of polar metabolites using a modified methanol:chloroform extraction (Bligh and Dyer, 1959), as previously described (Melvin et al., 2017, 2018). Following steps toward the investigation of metabolite profiles were similar to the ones described in Belivermis et al (2020) using the same type of equipment, software, spectra treatments and analyses (NMR being a $800 \mathrm{MHz}$ Bruker® Avance III HDX spectrometer equipped with a Triple -TCI- Resonance 5mm Cryoprobe and controlled with IconNMR ${ }^{\mathrm{TM}}$ software).

\subsection{Intestinal microbiome analysis}

Intestines from $n=4$ control fish and $n=4$ MP-exposed fish were dissected and stored in RNAlater at $-80{ }^{\circ} \mathrm{C}$ prior to $16 \mathrm{~S}$ sequencing. The samples were analyzed at the IGFL's Sequencing Platform (Lyon, France) in specific clean rooms dedicated to delicate DNA extraction and amplification. After RNAlater removal, total DNA was extracted from samples in 3 different sessions with an DNeasy PowerLyzer PowerSoil extraction kit (Qiagen ${ }^{\odot}$ ) following the manufacturer's recommendations with minor modifications. A mock extraction (no sample, only reagents) was added to monitor contamination during the DNA extraction process. The ION 16S Metagenomics kit (Thermo Fisher Scientific) was then used to amplify 
seven hypervariable regions (V2, V3, V4, V6, V7, V8, V9) of the $16 \mathrm{~S}$ in 6 fragments and 2 pools. The 16S fragments were amplified by Polymerase Chain Reaction (PCR) in duplicates with 30 cycles for each sample and the mock extraction. Two negative controls were also added at this step to monitor contamination from PCR reagents and aerosols. No contamination in the 3 negative controls (mock extraction, PCR reagents, aerosol) was detected for 30 cycles. For one MP fish, no positive amplifications being obtained with 30 cycles, a second PCR attempt with 35 cycles was performed on this sample along with negative controls. Faint positive amplifications were obtained for all conditions. Barcoded libraries were constructed for samples and for the pool of controls that were positive at 35 cycles using the Ion Xpress Plus gDNA Fragment Library Preparation Kit (Thermo Fisher Scientific) following manufacturer's instructions. Sequencing of bacterial 16S was performed on PGM Ion Torrent using a 318v2 chip and generated more than $6 \mathrm{M}$ reads. The reads were demultiplexed and analyzed with Ion Reporter (Thermo Fisher Scientific) using the dedicated Metagenomics w1.1 pipeline. Data obtained from consensus results were visualized and heatmaps were generated using SHAMAN (Quereda et al., 2016).

\subsection{Intestine and liver histologic analyses}

Intestines from $n=5$ control fish and $n=5$ MP-exposed fish, and livers from $n=3$ control fish and $n=3$ MP-exposed fish were used for histological analyses. During dissection, intestines were separated in 3 parts: anterior (i.e. 1 -cm long, right after the stomach), posterior (i.e. 1-cm long, right before the anus), and middle (i.e., in between the two previous section). Immediately after dissection, intestine parts and livers were fixed in PFA $4 \%$ at $4^{\circ} \mathrm{C}$ for $48 \mathrm{~h}$. They were then rinsed and conserved in Phosphate Buffered Saline $1 \mathrm{X}$ at $4^{\circ} \mathrm{C}$. The tissues were then dehydrated and embedded in paraffin. Cross-sections of $5 \mu \mathrm{m}$ were performed using a microtome, mounted on glass slides and stained with Hematoxylin and Eosin. Photographs were taken with an 
Olympus microscope and analyzed using Image $\mathbf{J}$ software (NIH). For each intestine part (i.e. anterior, posterior and middle) and for each liver, a total of 6 sections were made in the middle of the tissue: 3 successive sections (area 1) and 3 other successive sections $1 \mathrm{~mm}$ further in the tissue (area 2).

For each area, the highest quality (based on sectioning and staining) of the 3 sections was selected, resulting in 2 sections per intestine part and per liver per fish (i.e. one section for area 1 and another for area 2). On each intestine section, we measured the following parameters: (i) diameter (average of the longest and shortest diameters of the intestine cross section); (ii) outer longitudinal muscle layer (OLML) width, inner circular muscle layer (ICML) width, and villi length (averages of the measures made at four haphazardly selected locations); and (iii) number of goblet cells and villi surface area on four haphazardly selected villi (Fig. S1). For each histological section, villi length was used to calculate a villi length ratio (average villi length divided by the average intestine diameter), and goblet cell counts and villi surface area were used to estimate goblet cell density (number of goblet cells per $0.01 \mathrm{~mm}^{2}$ ). On liver sections, 5 haphazardly selected zones were photographed at a 40X magnification (Fig. S2). Each of these zones was then examined for fibrosis, hepatolysis and necrosis. Then, a grid of 20 circular subzones (each being a circle with a diameter of $40 \mu \mathrm{m}$, i.e. surface area of $1257 \mu \mathrm{m}^{2}$, and each circle being labelled from 1 to 20) was superposed on each of the photographs (Fig. S2). A total of 3 subzones were selected randomly (using the sample function in R). In each of these selected subzones, the number of hepatocyte nuclei and the number of erythrocytes were counted (Fig. S2), and these counts were respectively used as proxies for hepatocyte density (i.e. total number of hepatocytes per $1257 \mu \mathrm{m}^{2}$ ) and hepatic vascularization (i.e. total number of erythrocytes per $\left.1257 \mu \mathrm{m}^{2}\right)$. These parameters were monitored $\mathrm{n}=30$ times per fish ( 2 areas, 5 zones and 3 subzones per liver). In each of the selected subzones, 3 representative hepatocytes were haphazardly selected and measured for: (i) number of vacuoles, (ii) vacuole(s) area, and (iii) 
whole cell area. The ratio between these two areas was used as a marker of hepatocyte vacuolation. These measurements were therefore calculated on $n=90$ hepatocytes per fish (2 areas, 5 zones, 3 subzones and 3 hepatocytes per sub-zone).

\subsection{Ag and Zn assimilation efficiencies}

Determination of assimilation efficiencies of $\mathrm{Ag}$ and $\mathrm{Zn}$ by control and MP-exposed fish were performed using the gamma-emitting radiotracers ${ }^{110 \mathrm{~m}} \mathrm{Ag}$ and ${ }^{65} \mathrm{Zn}$ (Pouil et al., 2018a). More precisely, on the 20 fish (10 per diet group) that were haphazardly selected at the end of the MP exposure experiment, a pulse chase feeding was immediately conducted. We followed a protocol similar to the one used in Jacob et al. (2017). Specifically, live prey (brine shrimps) were radiolabeled using waterborne ${ }^{65} \mathrm{Zn}$ and ${ }^{110 \mathrm{~m}} \mathrm{Ag}$. These radiotracers $\left({ }^{65} \mathrm{Zn}\right.$ as $\mathrm{ZnCl}_{2}$ in $0.1 \mathrm{M}$ $\mathrm{HCl},\left[t_{1 / 2}=243.9\right.$ days $]$ and ${ }^{110 \mathrm{~m}} \mathrm{Ag}$ as $\mathrm{AgNO}_{3}$ in $0.1 \mathrm{M} \mathrm{HNO}_{3},\left[t_{1 / 2}=246\right.$ days $\left.]\right)$ were purchased from Isotope Product Lab., USA. Eighty grams of brine shrimp were placed in a 10 L Nalgen® bottle filled with $8 \mathrm{~L}$ of seawater spiked with ${ }^{110 \mathrm{~m}} \mathrm{Ag}$ and ${ }^{65} \mathrm{Zn}$ (activity of $15000 \mathrm{~Bq} \mathrm{~L}^{-1}$ for each radioisotope) for 48 hours. The brine shrimps were then collected with a hand-net, rinsed with 3 times $500 \mathrm{~mL}$ of non-contaminated seawater and paper-blotted before storage at $-20{ }^{\circ} \mathrm{C}$ until use. In each of the 4 aquaria ( 2 for the fish from the control diet and 2 for the fish from the MP diet, 5 fish per aquaria), a single feeding of $7.5 \mathrm{~g}$ of these radiolabeled thawed brine shrimps was performed. Fish ate all the brine shrimps in less than $10 \mathrm{sec}$. Then, 2 hours after the feeding, individual fish were $\gamma$-counted alive (whole-body measurement) and were then returned in their respective aquaria. As we wanted to follow the $\mathrm{Ag}$ and $\mathrm{Zn}$ depuration kinetics in individual fish, each one of them was identified using a combination of two visible implant fluorescent filaments (NMT, Shaw Island, USA), injected on the dorsal muscle two days prior to the experiment. Fish were again $\gamma$-counted (same procedure) on days 1, 2, 3, 4, 6, 9, 13 and 17 postfeeding to assess the depuration kinetics and assimilation efficiencies of the two elements (Pouil 
et al., 2018a). The $\gamma$-counting consisted of the quantification of both tracer radioactivity using high-resolution $\gamma$-spectrometer systems; four high-purity germanium (HPGe) $\mathrm{N}$ or P type detectors (EGNC 33-195-R, Canberra ${ }^{\circledR}$ and Eurysis $\left.{ }^{\circledR}\right)$ were used and these detectors were controlled by a multi-channel analyzer and a computer equipped with spectral analysis software (Interwinner® 6, Intertechnique). The radioactivity of each radiotracer was determined using calibrated standards of the same geometry. Measurements were corrected for background activity and radioactive decay. To ensure the accuracy of the gamma spectrometric analyses (Cresswell et al., 2017), fish were held in tubes positioned in circular boxes filled with noncontaminated seawater, ensuring that geometry was the same for each individual. The counting time was adjusted to obtain propagated counting errors typically less than 5\% (Metian et al., 2009), with run times being typically 5 to $10 \mathrm{~min}$, though longer count times were required towards the end of long-term depuration experiment (i.e. $\max 20 \mathrm{~min}$ ). Water temperature was stable in counting tubes and dissolved $\mathrm{O}_{2}$ concentrations were always $>3 \mathrm{mg} \mathrm{L}^{-1}$.

\subsection{Statistical analyses}

The influence of time and diet (i.e. control vs MP) on fish weight was assessed using linear models. The effect of diet on fish survival probability was assessed using Kaplan-Meier curves and log-rank test. The influence of diet on the carbon and nitrogen isotopic ratios was examined using a gamma generalized linear model and a linear model, respectively. NMR data was log transformed and auto-scaled using MetaboAnalyst, prior to being analyzed with Principal Component Analysis (PCA) to explore broad differences in whole-body metabolite profiles of the mussels. When moderate separation was observed via PCA, Sparse Partial Least Squares Discriminant Analysis (sPLS-DA) was subsequently applied to further highlight separation between treatment groups. Key metabolites contributing to metabolomic differences observed

with sPLS-DA were identified using Significance Analysis of Metabolites (SAM). The 
influence of MP exposure and intestine part on the intestine diameter, OLML, ICML and villi height ratio were assessed using gaussian and gamma Generalized Linear Mixed-effect Models (GLMM), with fish identity and histological section as random effects. The impact of MP on goblet cell density was examined using gamma GLMM with fish identity, histological section and villi (nested) as random effects. The effect of MP exposure on the number of hepatocyte nuclei and erythrocyte in liver subzones were investigated using Poisson GLMM, with fish identity, as well as histological section, zone and subzone (nested) as random effects. The influence of diet on hepatocyte vacuolation, hepatocyte vacuole number and hepatocyte surface area were examined using gaussian, negative binomial, and gamma GLMM, respectively. For these models, fish identity, as well as histological section, zone, subzone and hepatocyte identity (nested) were used as random effects. For each model, residuals were visually inspected to ensure that all assumptions were met. Non-linear mixed effect models were used to quantify the parameters of the two-component exponential equations for the depuration kinetics of each element and each diet, and to compare them across diets. For all statistical analyses, the level of significance was set at $\alpha=0.05$. All statistical analyses, excepting metabolomics, were performed using R (v3.5.3.). 


\section{Results}

\subsection{Weight and survival}

Fish weight was not influenced by the presence of MP in the $\operatorname{diet}\left(F_{1,197}=3.2 ; \mathrm{p}\right.$-value $\left.=0.075\right)$, and significantly increased with time for both fish groups $\left(F_{1,197}=100.2 ; \mathrm{p}\right.$-value $\left.<2 \mathrm{e}^{-16}\right)$ : from $8.9 \pm 0.1 \mathrm{~g}$ (mean $\pm \mathrm{SE}$ ) at D0, to $9.3 \pm 0.1 \mathrm{~g}$ at D14 and $10.7 \pm 0.2 \mathrm{~g}$ at D35 (Fig. 1a). In contrast, survival probability differed between diets, with lower survival in fish fed with MPcontaminated food compared to fish fed with control food $\left(\chi_{1}^{2}=10.9\right.$; -value $\left.=0.001\right)$ over the exposure period (Fig. 1b).

\subsection{Carbon and nitrogen stable isotope ratios}

While carbon stable isotope ratio was not affected by the MP $\operatorname{diet}\left(\chi_{1}^{2}=0.04 ; \mathrm{p}\right.$-value $\left.=0.841\right)$, the muscle samples of MP-exposed fish showed higher $\delta^{15} \mathrm{~N}$ values than control fish $\left(F_{1,24}=\right.$ 7.50; $p$-value $=0.011)$. Nevertheless, this difference was low and the proportion of carbon and nitrogen in the muscles samples from both fish groups did not differ across the two diets (Table 1).

\subsection{Primary metabolite profiles}

In the liver and brain samples, 28 and 35 NMR spectral features corresponding to 10 and 15 primary metabolites, respectively, were identified by SAM as driving the overall metabolic differences between control and MP-exposed fish (FDR adjusted p-values $=0.043$ and 0.034 , respectively). Specifically, relative abundances of inosine, phenylalanine, tyrosine, UDP glucose/galactose, glucose, mannose, betaine, sarcosine, alanine, and valine were higher in liver samples from MP-exposed fish vs control fish (Fig. 2a). Similarly, the relative abundances of 1-methylnicotinamide, phenylalanine, adenosine monophosphate, $\mathrm{N}$-acetylaspartate, aspartate, myo-inositol, creatine, glycine, taurine, gamma-aminobutyric acid (GABA), glutamate, 
glutamine, acetamide, alanine, and leucine were higher in the MP-exposed fish brain samples than in control fish (Fig. 2b). In contrast, the PCA of polar metabolites extracted from muscle tissue identified very little difference between control fish and those exposed to microplastics. With this outcome, no supervised multivariate analysis or additional interpretation was performed on muscle extracts.

\subsection{Intestinal microbiome}

Seven intestinal samples out of the eight gave $16 \mathrm{~S}$ results. The MP-4, for which the $16 \mathrm{~S}$ was difficult to amplify and very few reads of bacterial origin were finally obtained, was not considered further in the analyses. The $7 S$. aurata juvenile samples $(\mathrm{n}=4$ for Control and $\mathrm{n}=$ 3 for MP treatment) show different $16 \mathrm{~S}$ profiles, with an $\alpha$-diversity ranging between 17 and 29 order overall. Three orders of bacteria were observed as most abundant in fish intestines but in variable proportion: Vibrionales (Proteobacteria), Micrococcales and Nakamurellales (Actinobacteria; Fig. 3a). At the family level, the PCoA analysis shows two groups of samples divided on the first axis (Fig. 3b). The first group, three control fish (CT-1, CT-2, CT-4) and one MP-treated (MP-1), has a high proportion of Vibrionaceae (Vibrionales $>80 \%$ ). The other group, one control fish (CT-3) and two MP fish (MP-2 and MP-3), has a more diversified bacterial composition with 4 main families in quite similar proportion: Demequinaceae, Cellulomonadaceae, Nakamurellaceae and Vibrionaceae (Fig. 3c). Among the first group, MP1 is characterized by a different signature with Photobacterium genus composing most part of the Vibrionacea while Vibrio is the most abundant genus of this family for the 3 controls. MP1 also shows a higher percentage of Micrococcales that is not observed in the 3 controls (Fig. 3a). 


\subsection{Intestine and liver histology}

Average intestine diameter did not vary across intestine parts (i.e. anterior, middle, and posterior, $\chi_{2}^{2}=0.248 ; \mathrm{p}$-value $=0.884$ ), nor between diets (i.e. control $v s \mathrm{MP} ; \chi_{1}^{2}=2.47$; value $=0.412$; Fig. S3a). This was also the case for ICML (Fig. S3c) and for villi height ratio (Fig. S3d), while OLML varied across the intestine parts $\left(\chi_{2}^{2}=12.37\right.$; -value $\left.=0.002\right)$ and was significantly lower in MP-exposed fish vs control fish in the middle part of the intestine only (Fig. S3b). Goblet cell density also varied across intestine parts (i.e. the posterior the intestine section the higher the goblet cell density; $\chi_{2}^{2}=30.91 ; \mathrm{p}$-value $=1.937 \mathrm{e}^{-07}$ ) and across diets $\left(\chi_{1}^{2}=3.91 ; \mathrm{p}\right.$-value $\left.=0.048\right)$, the latter being essentially driven by the low goblet cell density observed in the middle part of the intestine in MP-exposed fish (Fig. 4a,b).

We found no particular pattern of fibrosis, hepatolysis, nor necrosis in livers from control or MP-exposed fish. While MP diet also did not affect hepatic vascularization $\left(\chi_{1}^{2}=0.57\right.$; value $=0.448)$, it lowered hepatocyte density $\left(\chi_{1}^{2}=14.60 ; p\right.$-value $=1.331 \mathrm{e}^{-4} ;$ Fig. $\left.4 \mathrm{~d}\right)$. Moreover, hepatocytes from fish exposed to MP in their diet exhibited increased vacuolation $\left(\chi_{1}^{2}=32.21 ; \mathrm{p}\right.$-value $=1.386 \mathrm{e}^{-08} ;$ Fig. $\left.4 \mathrm{c}, \mathrm{e}\right)$ compared to control fish, but similar number of vacuoles $\left(\chi_{1}^{2}=0.026 ; \mathrm{p}\right.$-value $\left.=0.871\right)$ and surface area $\left(\chi_{1}^{2}=0.746 ; \mathrm{p}\right.$-value $\left.=0.388\right)$.

\subsection{Assimilation efficiency}

Whole-body depuration kinetics of ${ }^{65} \mathrm{Zn}$ and ${ }^{110 \mathrm{~m}} \mathrm{Ag}$ were best fitted against two-component exponential models, for both diet groups (Fig. 5a,b, Fig. S4). The remaining activity of each element in each group can be modelled as follow: $\mathrm{A}_{0 \mathrm{~s}} * \mathrm{e}^{-\mathrm{Kes}^{*} \mathrm{t}}+\mathrm{A}_{01} * \mathrm{e}_{-} \mathrm{Kel}^{*}$; where $\mathrm{A}_{0 \mathrm{~s}}, \mathrm{~K}_{\mathrm{es}}, \mathrm{A}_{01}$ and $\mathrm{K}_{\mathrm{el}}$ are specific to each element and each fish diet group (Fig. S4) and where $t$ is time. Moreover, both ${ }^{65} \mathrm{Zn}$ and ${ }^{110 \mathrm{~m}} \mathrm{Ag}$ depuration kinetics differed across diets $\left(F_{4,162}=6.83 ; \mathrm{p}\right.$ value $=4.071 \mathrm{e}^{-05}$ and $F_{4,162}=9.75 ; \mathrm{p}$-value $=4.134 \mathrm{e}^{-07}$, respectively). In particular, non-linear 
mixed-effect models revealed that MP-exposed fish exhibited significantly higher $\mathrm{A}_{01}$ for ${ }^{65} \mathrm{Zn}$ $\left(F_{1,161}=6.73 ;\right.$ p-value $=0.01 ;$ Fig. $\left.5 \mathrm{c}\right)$, and a lower $\mathrm{A}_{01}$ for ${ }^{110 \mathrm{~m}} \mathrm{Ag}\left(F_{1,161}=10.54 ; \mathrm{p}\right.$-value $=$ 0.001; Fig. 5d).

a
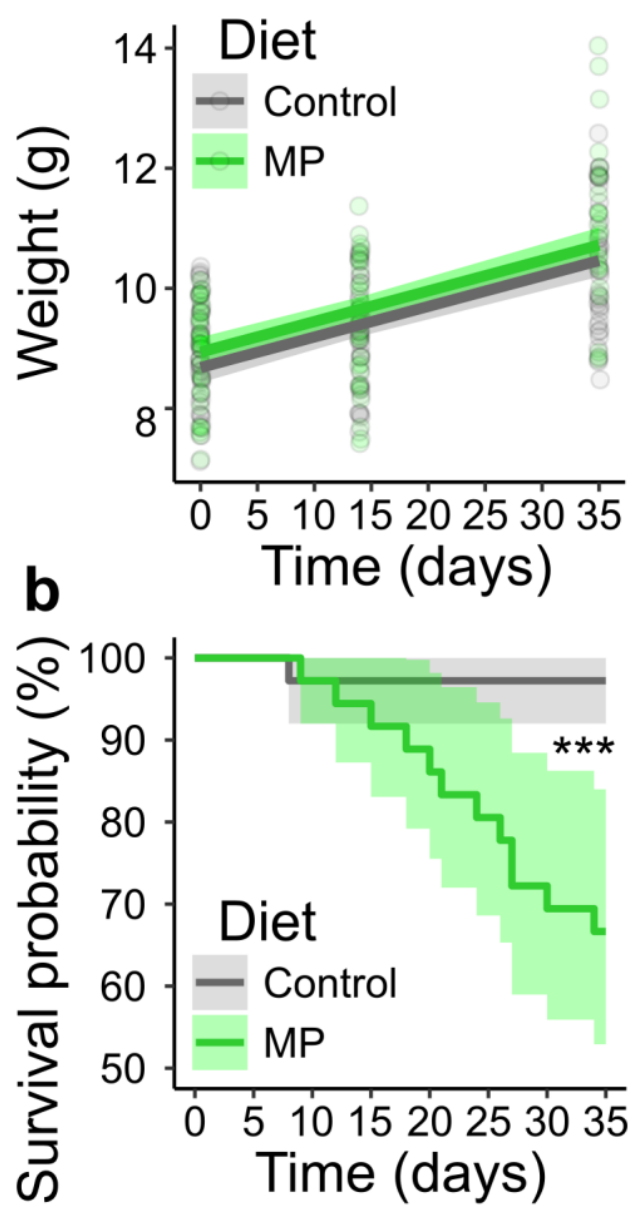

Figure 1. Fish weight variations (a) and survival probability (b) across time and diets. Fish weights $(n=200)$ were measured at the start of the microplastics (MP) exposure experiment, after 14 days, and at the end (35 days) of the exposure period, in both the control and MP-exposed fish. Survival curves correspond to Kaplan-Meier curves and *** indicates $\mathrm{p}$-value $=0.001$ from the log-rank test comparing the survival of fish exposed to control diet vs diet containing MP. In both (a) and (b) lines and ribbons indicate model outputs with $95 \%$ confidence intervals, while transparent jittered circles in (a) indicate each data point. 


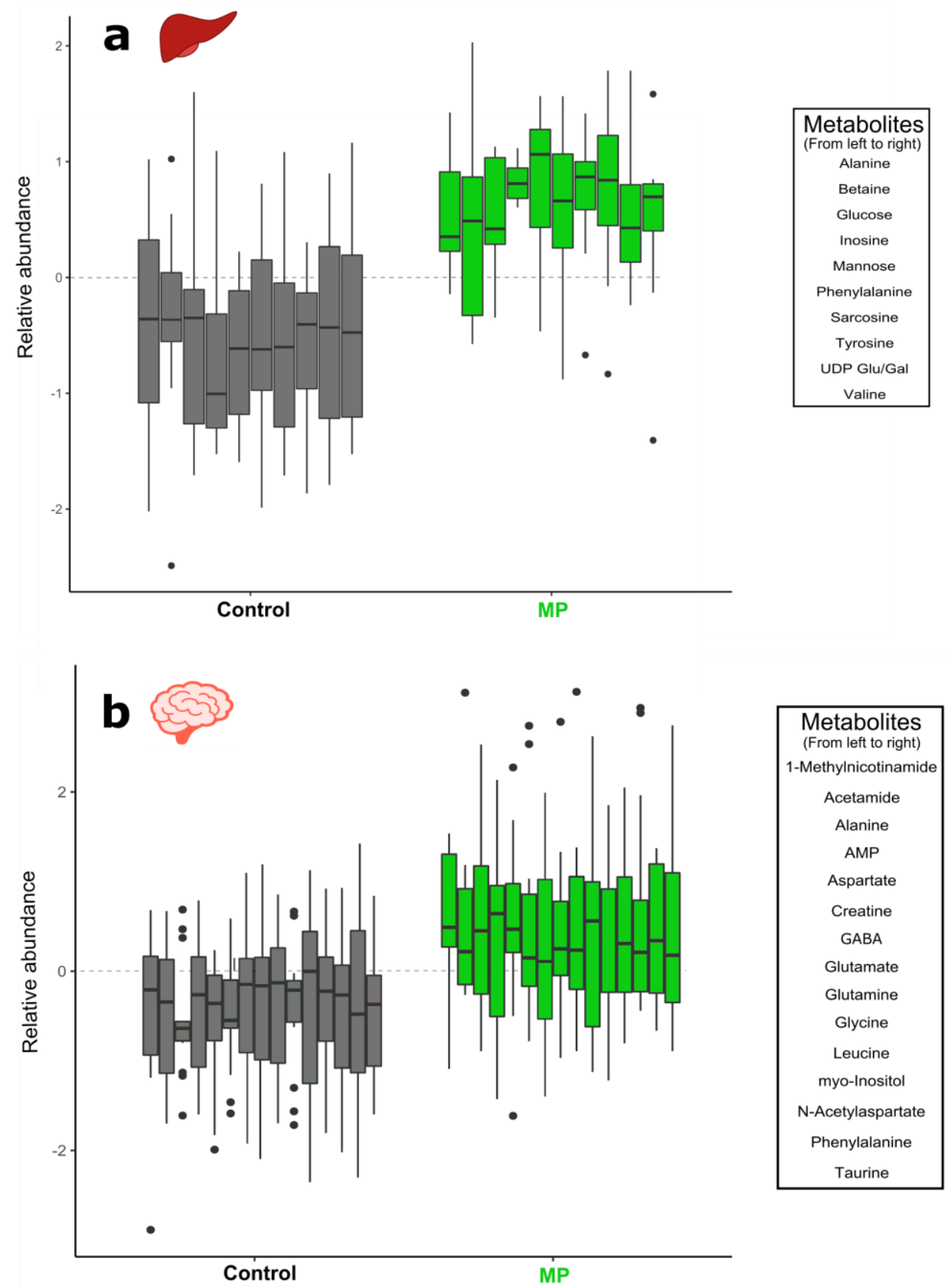

Figure 2. Hepatic (liver) polar metabolites (A) and Brain polar metabolites (B) identified as occurring at significantly different relative abundance in control fish compared to fish exposed to microplastics (MP) for 35 days, based on findings of SAM analysis. 


\begin{tabular}{|l|c|c|c|c|c|c|c|}
\hline ORDERS & CT-1 & CT-2 & CT-3 & CT-4 & MP-1 & MP-2 & MP-3 \\
\cline { 1 - 9 } Alteromonadales & 6,7 & 6,2 & 0,2 & 4,5 & 1,9 & 0,9 & 9,1 \\
Brevinematales & 0 & 0 & $<0,1$ & 1,7 & 1,3 & 0,3 & $<0,1$ \\
Burkholderiales & 3,8 & 1 & 0,8 & 0,2 & 4,5 & 0,9 & 0,2 \\
Clostridiales & 0 & 0 & 4,5 & 0 & $<0,1$ & 0 & 5,7 \\
Lactobacillales & $<0,1$ & 0,1 & 0,9 & 0 & 0,5 & 1,5 & 0,1 \\
Pseudomonadales & 2,2 & 0,8 & 0,6 & 0,2 & 1,9 & 0,5 & $<0,1$ \\
Rhodobacterales & 0,3 & 2,4 & 0,6 & $<0,1$ & $<0,1$ & 0,4 & 0,3 \\
Vibrionales & 85,6 & 87,7 & 14,9 & 93,0 & 82,3 & 14,3 & 29,0 \\
Micrococcales & 0,6 & 0,3 & 55,7 & 0,1 & 5,0 & 64,4 & 45,6 \\
Nakamurellales & 0 & $<0,1$ & 19,0 & $<0,1$ & 1,7 & 15,9 & 9,5 \\
\hline
\end{tabular}
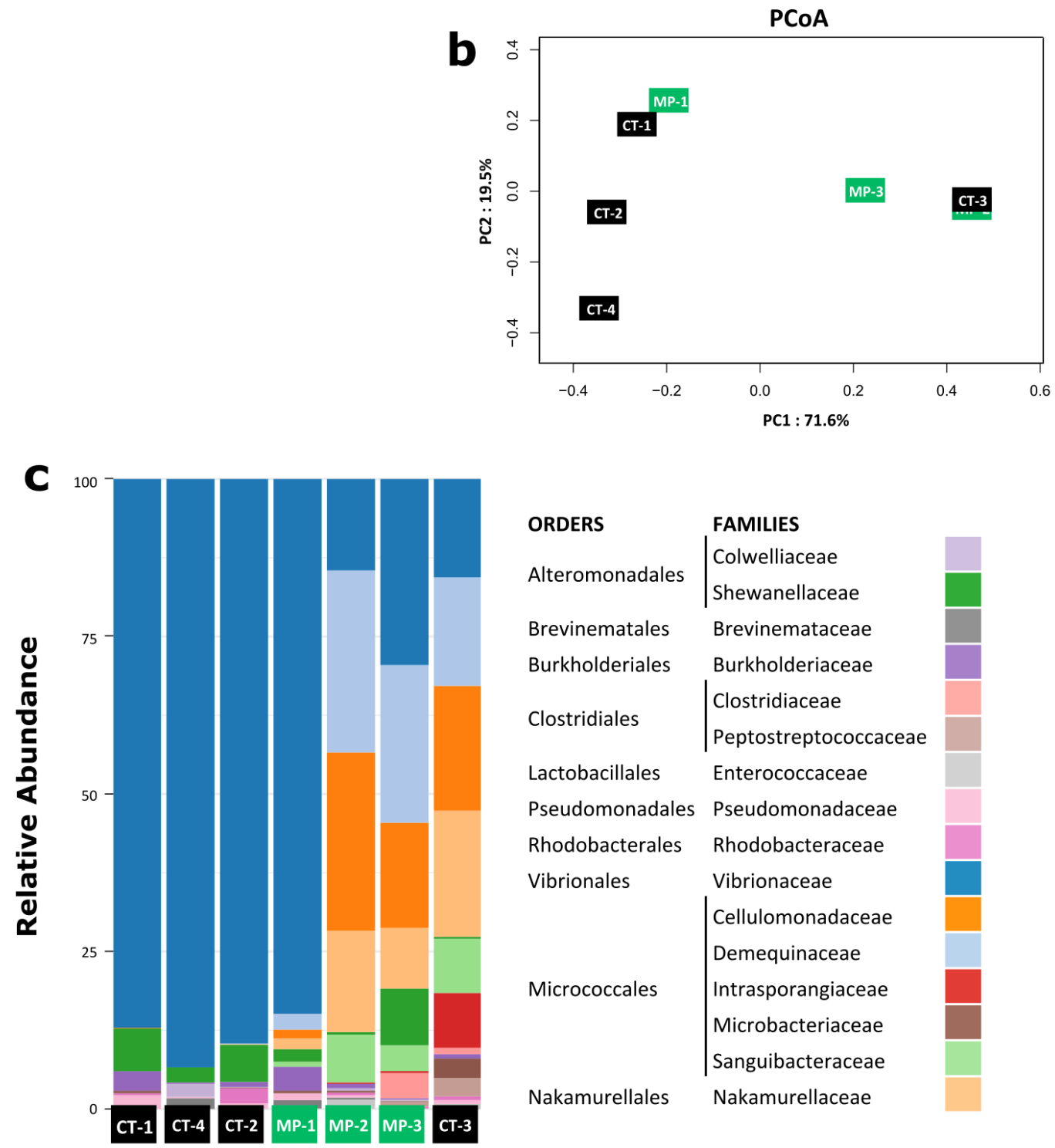

\begin{tabular}{ll} 
ORDERS & FAMILIES \\
Alteromonadales & $\begin{array}{l}\text { Colwelliaceae } \\
\text { Shewanellaceae }\end{array}$ \\
Brevinematales & Brevinemataceae \\
Burkholderiales & \multicolumn{1}{|c}{ Burkholderiaceae } \\
Clostridiales & $\begin{array}{l}\text { Clostridiaceae } \\
\text { Peptostreptococcaceae }\end{array}$ \\
Lactobacillales & Enterococcaceae \\
Pseudomonadales & Pseudomonadaceae \\
Rhodobacterales & Rhodobacteraceae \\
Vibrionales & Vibrionaceae \\
Micrococcales & $\begin{array}{l}\text { Cellulomonadaceae } \\
\text { Demequinaceae } \\
\text { Intrasporangiaceae }\end{array}$ \\
& $\begin{array}{l}\text { Microbacteriaceae } \\
\text { Sanguibacteraceae }\end{array}$ \\
Nakamurellales & Nakamurellaceae
\end{tabular}

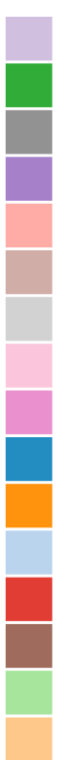

Figure 3. Effect of MP exposure on the composition of intestinal microbiome in juveniles $S$. 
aurata, based on 16S RNA sequencing. (A) Bacteria diversity observed at the order level between control fish (CT, black) and MP-exposed fish (MP, green) fish. (B) Principal Coordinates Analysis (bray distance) at the family level. (C) Barplot profiles generated for each sample at the family level. For every analysis $n=4$ for Control and $n=3$ for MP treatment. 
a
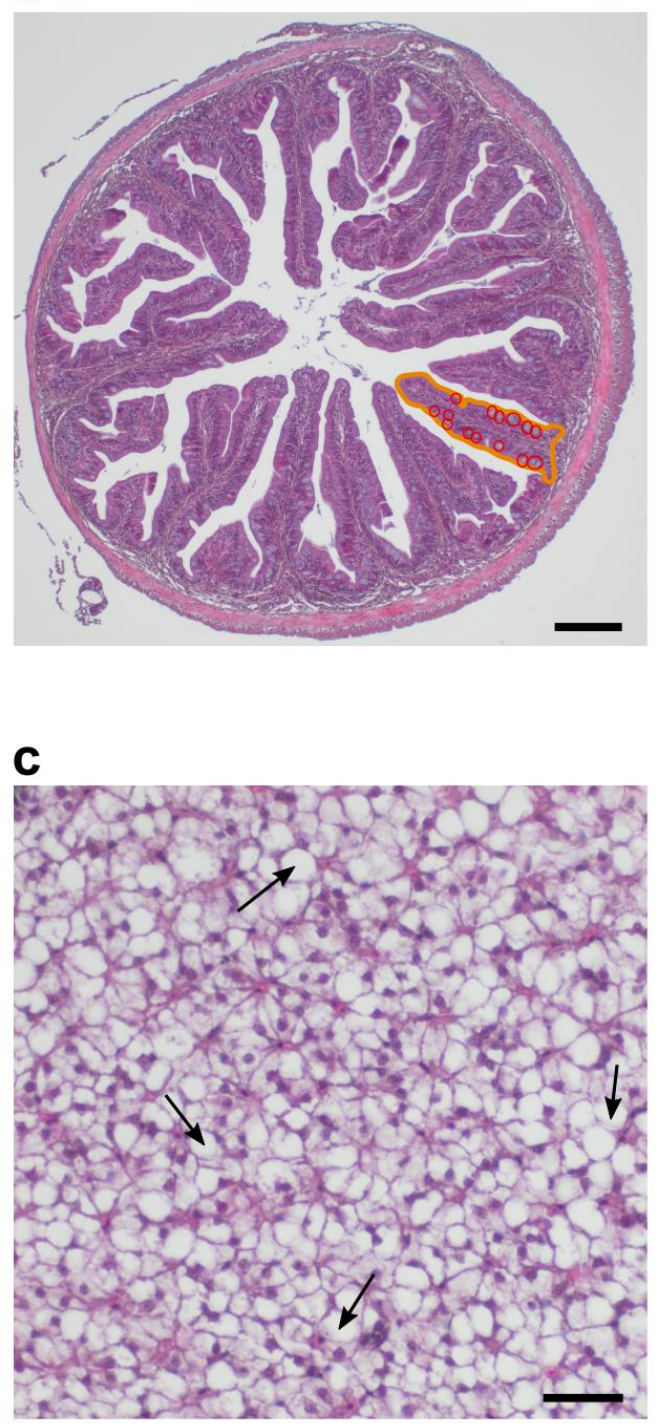

b

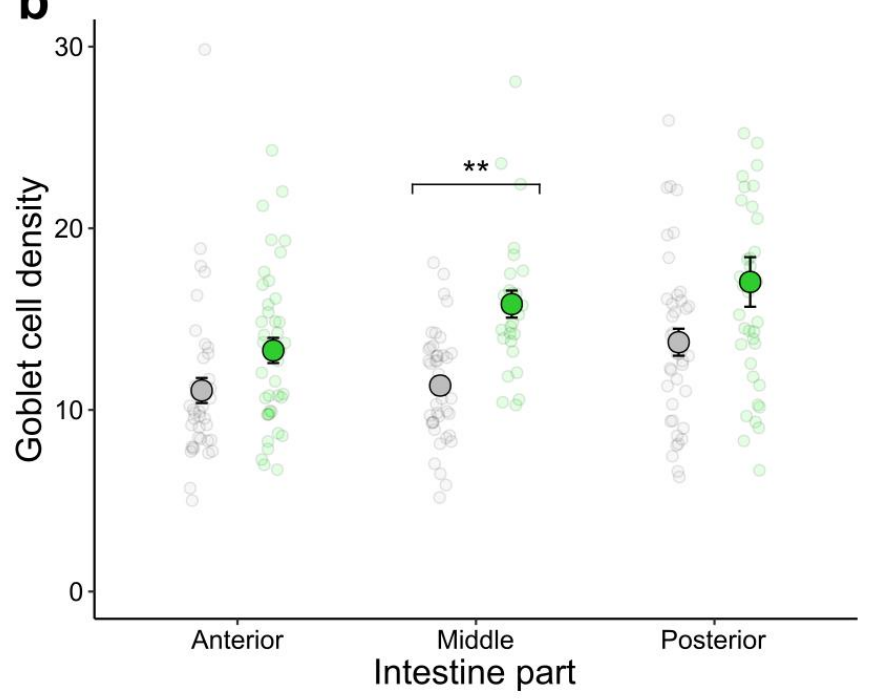

d

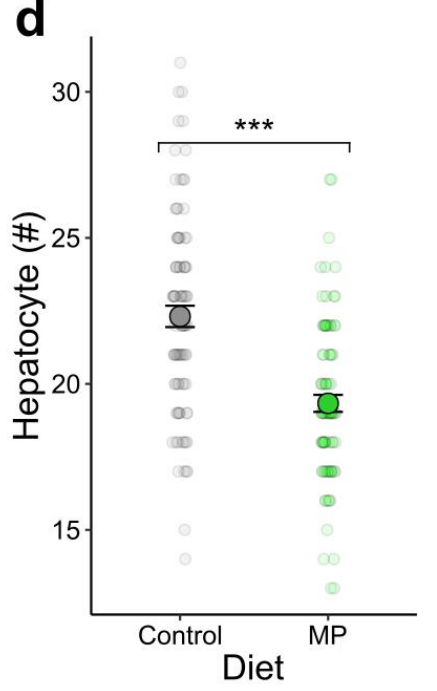

e

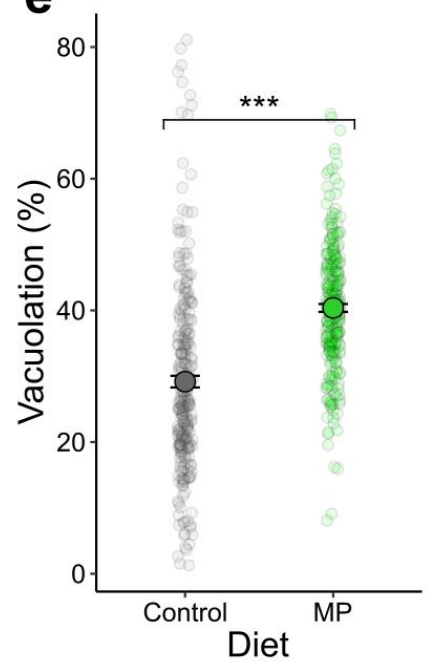

Figure 4. Intestine and liver histopathology of fish exposed to MP. Data are indicated as mean $\pm \mathrm{SE}$, with transparent jittered circles indicating each data point. (a) Cross-section of a juvenile S. aurata intestine, showing a villi surface area (orange) and goblet cells (circled in red). Scale bar: $100 \mu \mathrm{m}$. (b) Variation of goblet cell density (i.e. number of cells per $0.01 \mathrm{~mm}^{2}, \mathrm{n}=240$ ) across intestine parts and diets (gray and green circles for the control and the MP diet, respectively). ** indicates p-value $<0.01$ from a posthoc test following gamma GLMM. (c) Liver cross section of a juvenile $S$. aurata showing vacuolated hepatocytes (see arrows for examples). Scale bar: $20 \mu \mathrm{m}$. Example of control non vacuolated hepatocyte is provided in Fig. S2. (d) Variation of hepatocyte density (number of hepatocytes in $1257 \mu \mathrm{m}^{2}$ subzones, $\mathrm{n}=180$ ) across diets. (e) Hepatocyte vacuolation $(\mathrm{n}=540)$ in control $v s$ MP-exposed fish. *** indicates p-value $<0.001$ from posthoc tests following Poisson and gaussian GLMM in (d) and (e), respectively. 

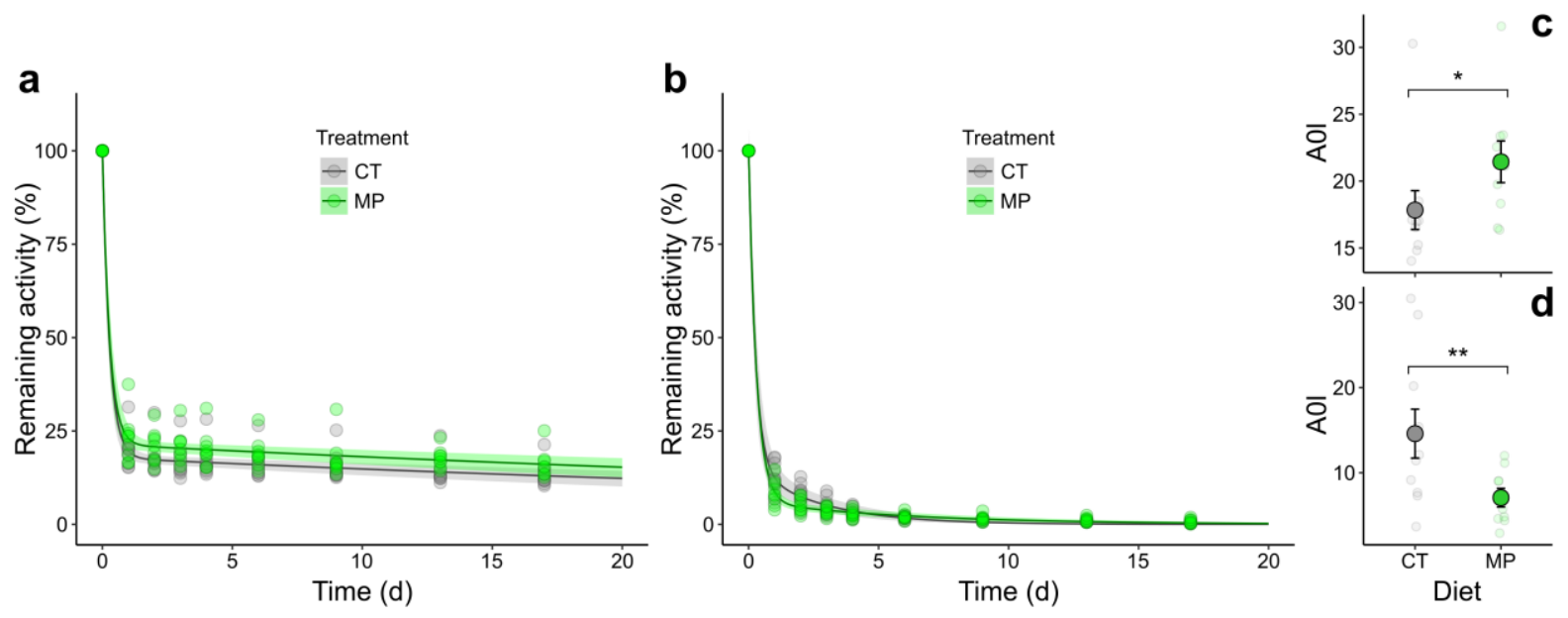

Figure 5. Depuration kinetics of ${ }^{65} \mathrm{Zn}$ (a) and ${ }^{110 \mathrm{~m}} \mathrm{Ag}(\mathrm{b})$ in Sparus aurata juveniles $(\mathrm{n}=170)$ over a 17-day period and in control and MP diets. Both depuration kinetics follow a biexponential equation: remaining activity $=\mathrm{A}_{0 \mathrm{~s}} * \mathrm{e}^{-\mathrm{Kes}^{*} \mathrm{t}}+\mathrm{A}_{01} * \mathrm{e}^{-\mathrm{Kel} * \mathrm{t}}$; with $\mathrm{A}_{0 \mathrm{~s}}, \mathrm{~K}_{\mathrm{es}}, \mathrm{A}_{01}$ and $\mathrm{K}_{\mathrm{el}}$ being constant that are specific to each element and each fish diet group (Fig. S4). Lines and ribbons indicate non-linear mixed effect model predictions \pm SE. $A_{01}$ is a good indicator of assimilation efficiency and varied for both ${ }^{65} \mathrm{Zn}(\mathrm{c})$ and ${ }^{110 \mathrm{~m}} \mathrm{Ag}(\mathrm{d})$ across diets. Specifically, * and $* *$ indicate $\mathrm{p}$-values $<0.05$ and 0.01 , respectively, from non-linear mixed-effects models. In (c) and (d) gray and green circles indicate data (mean \pm SE) for control and MP-exposed fish, respectively, and transparent jittered circles indicate each data point. 
Table 1. Carbon $(\mathrm{C})$ and nitrogen $(\mathrm{N})$ isotopic ratios and percentages in muscle samples from fish exposed to control diet vs microplastic (MP) diet, as well as in brine shrimp samples (whole body) and MP particles. $\% \mathrm{C}$ and $\% \mathrm{~N}$ indicate the percentage of $\mathrm{C}$ and $\mathrm{N}$ in the whole sample, respectively. Data are indicated as mean $\pm \mathrm{SE}$.

\begin{tabular}{cccccc}
\hline Sample & $\mathbf{n}$ & $\boldsymbol{\delta}^{\mathbf{1 3}} \mathbf{C}(\mathbf{\%})$ & $\mathbf{\%} \mathbf{C}$ & $\boldsymbol{\delta}^{\mathbf{1 5}} \mathbf{N}(\mathbf{\%})$ & $\boldsymbol{\%} \mathbf{N}$ \\
\hline Control fish muscle & 12 & $-18.43 \pm 0.10$ & $44.93 \pm 0.24$ & $12.92 \pm 0.05$ & $13.36 \pm 0.14$ \\
MP fish muscle & 14 & $-18.41 \pm 0.09$ & $44.63 \pm 0.36$ & $13.14 \pm 0.06$ & $13.33 \pm 0.22$ \\
Artemia whole body & 3 & $-20.52 \pm 0.03$ & $40.02 \pm 0.25$ & $13.261 \pm 0.03$ & $8.74 \pm 0.03$ \\
MP particles & 1 & -29.64 & 73.11 & -2.392 & 1.39 \\
\hline
\end{tabular}




\section{Discussion}

During the past decade, the potential toxicity of MP on fish physiology and biological parameters has been explored in several experimental studies (reviewed by de Sá et al., 2018; Foley et al., 2018; Franzellitti et al., 2019). These studies have used a variety of fish species, MP types and shapes, and have generally considered a limited number of biological indicators within individual studies (Jacob et al., 2020). Therefore, no clear consensus exists on the effects of MP on fish or the mechanistic underpinnings leading to effects. Here, a series of toxicological indicators were used, spanning multiple biological levels of organization (from atomic to organismal levels) to better understand responses and possible physiological mechanisms in juveniles of a common marine fish model (Sparus aurata) exposed to PE-MP (10-20 $\mu \mathrm{m})$. S. aurata were exposed to a high concentration of $48180 \pm 10074$ MP per fish per day, which is several orders of magnitude higher than exposures reported in aquatic environments, but which results from MP naturally accumulated by the living brine shrimps that we used as exposure diet. Moreover, since the goal of the present study was to investigate the toxicity and potential mechanisms of toxicity of MP ingestion in fish by using a wide range of biological markers, this high concentration was used to maximize significant effects of MP ingestion on those biological functions.

We observed significant alterations to several biological markers in S. aurata exposed to MP. First, assimilation of an essential element was affected by MP exposure. Indeed, while ${ }^{110 \mathrm{~m}} \mathrm{Ag}$ was not assimilated in either experimental treatment, $\mathrm{Zn}$ assimilation efficiency (AE) was observed to be significantly higher in MP-exposed fish (Fig. 2). While $\mathrm{Zn} \mathrm{AE}$ in fish can occasionally be affected by environmental variable (e.g. temperature but not $\mathrm{pH}$; Pouil et al., 2018), here we shown that 35-d of MPs ingestion can influence assimilation processes of an essential element in juvenile $S$. aurata digestive tract. This could perturb proper nutrition of the 
fish since the digestive tract is not only a major uptake site for $\mathrm{Zn}$ but serves also as an important sink for Zn storage (Hogstrand and Wood, 2010). Zn is known to be essential for the proper maintenance of intestinal tight junctions (Guthrie et al., 2015), which have been previously shown to be affected by MP exposure in fish (Qiao et al., 2019). Hence, increased Zn assimilation may suggest a compensatory mechanism to restore intestinal tight junctions, or alternatively may reflect increased available $\mathrm{Zn}$ pools in the absence of tight junctions. Since $\mathrm{Zn}$ is implicated in a range of cellular functions (Hogstrand and Wood, 2010), these hypotheses are as of yet largely speculative and require further attention. On the other hand, the absence of MP-induced assimilation of a contaminant such as Ag, and the absence of effects of MP ingestion on $S$. aurata muscle $\mathrm{C}$ and $\mathrm{N}$ isotopic profiles, are important to note in the context of human consumption of this species.

Changes in metabolite profiles have previously been reported following MP exposure in fish, but with conflicting outcomes. Consistent with our findings, Qiao et al. (2019) observed broad increases in most liver metabolites in zebrafish exposed to $5 \mu \mathrm{m}$ PS-MP. Wan et al. (2019) showed more contrasted changes in their study, perhaps due to the type of metabolite profiling performed (i.e., whole zebrafish analyzed compared to specific organ), but again described an overall increase in most metabolites when fish were exposed to MP. This included increased glucose (Wan et al., 2019), which was also a prominent metabolite change observed in the present study. Our analysis using NMR revealed 10 and 15 metabolites were largely responsible for the overall differences in liver and brain of MP-exposed fish compared to controls (Fig. 3). Due to the relatively few studies exploring effects of MP exposure on metabolite profiles of fish, it is difficult to make inferences on underlying mechanisms responsible for the observed changes. However, by highlighting similarities emerging across these limited studies it is possible to identify patterns that may have relevance for possible mechanisms. Specifically, the 
studies performed thus far suggest that, after MP exposure, a collective increase in various metabolites occurs rather discrete changes to a few individual metabolites. This could suggest a general disturbance of cellular function rather than specific effects due to the interaction of the MPs with a distinct cellular process, as discussed by some authors (Mattsson et al., 2015; Tang, 2017). Indeed, Tang (2017) proposed that metabolic alterations may have limited specific relevance and support more the notion of broad inflammatory responses or alterations to nutrient uptake and assimilation. Changes observed in the brain metabolite profile could also possibly arise from broad effects related to nutrition. For example, the gut microbiota of vertebrates plays critical roles in a variety of biological processes such as nutrition, development, metabolism, immunity and resistance to invasive pathogens (Clemente et al., 2012; Yamashiro, 2018). Recent studies identified links between the gut microbiota and brain neuromodulation (Filosa et al., 2018; Martin et al., 2018), and alterations to the gut microbiota can increase the gut permeability and the translocation of metabolites and bacteria through the intestinal barriers, potentially influencing the gut-liver and gut-brain axis (Yarandi et al., 2016). While no significant differences were observed between the gut microbiome of MP-exposed and control fish in our study some interesting trends did arise, with two distinct patterns in microbiome composition emerging in control and MP-exposed fish.

Overall, the main dominant phylum in seabreams gut were Proteobacteria (Vibrionales, Alteromonadales) and/or Actinobacteria (Micrococcales, Nakamurellales). The prevalence of Proteobacteria in the gut microbiome of $S$. aurata is consistent with previous report on this species(Kormas et al., 2014), and in fish in general (Sullam et al., 2012). Despite the lack of statistical differences in the present study, the relative abundance of these two dominant phyla differed quite markedly between 2 MP-exposed and 3 control fish, with MP-exposed fish having a higher relative abundance of Actinobacteria compared to Proteobacteria, and control 
fish showing the opposite trend (Fig. 3). This was translated to a higher relative abundance of Micrococcales (Cellulomonadaceae, Demequinaceae) and Nakamurellales, and to a lower relative abundance of Vibrionales (Vibrionaceae) at the order level in MP-exposed fish (Fig. 3). To the best of our knowledge, no studies have looked at the effect of the trophic transfer of MP on the gut microbiome of fish, but some studies investigated the effect of PS-MP contaminated water on the zebrafish Danio rerio (Jin et al., 2018; Qiao et al., 2019; Wan et al., 2019). While the MP type, exposure pathway, fish life stage and diet all varied between these studies and the current study, we nevertheless note a systematic decrease of Proteobacteria abundance. Importantly, Proteobacteria are known to influence fat levels in the liver of humans (Spencer et al., 2011), which is consistent with our observation of increased hepatocyte vacuolation. The gut microbiome is also tightly connected to metabolism in various organisms (Yamashiro, 2018), and has been shown to be affected by MP exposure in several studies (Mu et al., 2015; Qiao et al., 2019; Wan et al., 2019). The central role of the intestinal microbiome highlights an urgent need to better examine its sensitivity to MP exposure, as this could conceivably be a key initiating mechanism linked to all the biological impairments observed in this study, and in past studies. Based on these promising preliminary results, similar studies monitoring more individuals and taking into account, at the start of the experiment, a potential initial variability in microbiome diversity of fish, may therefore be a useful tool when trying to understand the underlying mechanisms of the effect of MP in fish (Fackelmann and Sommer, 2019).

In this study, MP-exposed fish showed higher rates of hepatocyte vacuolation (Fig. 5A), as well as lower densities of hepatocytes than control fish (Fig. 5B). The liver is one of the most intensively investigated organs in fish toxicological studies, due to its vital functions and key role in detoxification processes, energy metabolism and storage, food digestion and the 
synthesis of proteins (Hinton et al., 2017; Van der Oost et al., 2003; Wolf and Wheeler, 2018). At the subcellular level, vacuolation may indicate energy storage in the form of glycogen or lipids, or it may reflect a degenerative change caused by fluid distension of organelles and/or an accumulation of free fluid in the cytoplasm (Wolf and Wheeler, 2018). Such degenerative change have been related to energy depletion and inhibition of protein synthesis in response to chemical stress in liver of fish (Wolf and Wheeler, 2018). Histological damage has been previously observed in the liver of fish exposed to MP. Jabeen et al. (2018) reported passive hyperaemia, dilated sinusoids, and hydrophic vacuolization in the liver of goldfish (Carassius auratus) exposed to MP (fibers). Inflammatory responses and lipid droplets have also been reported in the liver of zebrafish exposed to $5 \mu \mathrm{m}, 20 \mu \mathrm{m}$, or $70 \mathrm{~nm}$ polystyrene MP (Lu et al., 2016). Finally, an elevated degree of tissue change has been reported in the liver of juvenile African catfish (Clarias gariepinus) exposed to virgin PE-MP fragments (Karami et al., 2016). Given the widespread reported liver impairments in fish exposed to MP, this appears as an important target organ of MP toxicity.

Mortality was significantly higher for PE-MP-exposed fish compared to control (Fig. 1), which can be viewed as the highest possible toxicological response of an organism to a stressor. Although most previous studies have not reported significant mortality in fish exposed to MP (e.g. Barboza et al., 2018c; Choi et al., 2018b; Jabeen et al., 2017), increased mortality rates have been observed in a few studies. For example, zebrafish (Danio rerio) exposed to $10 \mathrm{mg} \mathrm{L}^{-}$ ${ }^{1}$ of $70 \mu \mathrm{m}$ PP-MP via water for 10 days showed higher mortality rates than their control counterparts (Lei et al., 2018). The same observations were made for common gobies (Pomatoschistus microps) exposed to $216 \mu \mathrm{g} \mathrm{L} \mathrm{L}^{-1}$ of $1-5 \mu \mathrm{m}$ PE-MP via water during 4 days (Luís et al., 2015) and for larval European seabass (Dicentrarchus labrax) exposed to 200 PEMP day ${ }^{-1}(10-45 \mu \mathrm{m})$ via food for 36 days (Mazurais et al., 2015). Mortality is a non-specific 
outcome that is often difficult to attribute to any particular biological alteration related to toxicity, and it is even more complex to understand the underlying cause of mortality in response to MP-exposure. The high biological complexity of organisms like fish, combined with the numerous possibilities for direct and indirect effects of MP on biological functions and the limited variety of biological indicators normally assessed, make it difficult to draw mechanistic conclusions about the effects of MP on fish. The use of several biological indicators in parallel offers some insights regarding the mechanisms behind MP-induced mortality in fish. MP ingestion has been shown to cause intestinal blockage and damage in various marine organisms, which may ultimately result in starvation, impaired digestive processes and/or reduced nutrient uptake (also termed nutrient dilution) ultimately culminating in reduced growth (Egbeocha et al., 2018; McCauley and Bjorndal, 1999; Welden and Cowie, 2016). Here, S. aurata juveniles exposed to PE-MP for 35 days showed no clear histological intestinal damage (data not shown), no altered growth and no difference in metabolite profiles or C/N ratios in muscle tissue (Table 1). This suggests limited to no effect of spherical virgin PE-MP on digestive tract integrity or subsequent nutrient assimilation in this species. These results are consistent with the literature showing that spherical MP are less prone to alter the integrity of the digestive tract of fish compared to MP fragments and fibers (Jabeen et al., 2017; Jovanović et al., 2018). In addition, the small dimension of the MP used (10-20 $\mu \mathrm{m})$ would be very unlikely to cause intestinal blockage in juveniles seabreams. It therefore seems unlikely that increased mortality of MP-exposed fish observed in this study was due to food deprivation, starvation or affected digestion, but more probably to other mechanisms.

While behavior was not a direct endpoint measured in this study, fish exposed to MP were observed to behave more aggressively than controls, with several attacks observed between fish over the exposure period (Jacob personal observation). Aggressions may therefore be a 
causative factor contributing to death of MP-exposed fish, and this warrants further study. Aggression is often displayed as a mechanism to cope with a social challenge or stressor in vertebrates (Verona and Kilmer, 2007) and may reflect alterations to the internal state of fish (Martins et al., 2012). Physiological stress induced by MP exposure could thus conceivably result in increased aggressive behavior by $S$. aurata. As discussed previously, several biological indicators of fish exposed to MP were significantly different from controls in this study (i.e. assimilation efficiency of $\mathrm{Zn}$, metabolites in brain and liver, and hepatocyte morphology), with marginal effects on other indicators (e.g. gut microbiome). We hypothesize that altered physiological parameters, caused by MP exposure, could influence fish aggressive behavior thereby indirectly contributing to mortality. However, it is not possible to offer conclusive evidence to this effect based on the present study, and entirely possible that physiological effects caused by MPs are themselves directly related to the observed mortality, thus more research is necessary.

Exposure to a high dose of 10-20 $\mu \mathrm{m}$ MP for 35 days increase mortality and resulted in broad modification to various biological functions of a marine fish species, the seabream Sparus aurata. We suggest several possible explanations for the observed mortality in MP-exposed fish: 1) either the combined physiological stress associated with MP ingestion caused direct mortality, for example through immune suppression, 2) physiological alterations resulted in increased aggression between fish that ultimately resulted in death, or 3) some combination of these. One potential bias of our results relates to an absence of physiological analyses on the fish that died during the exposure, which could have reduced or enhanced certain differences between MP-exposed fish and controls (i.e. survivor bias, Saunders and Hoppa, 1993). Hence, further studies are needed to explore these possibilities, and to investigate other biological functions such as the immunological function and behavioral state of MP-exposed fish. It is 
also worth noting that the results presented in this study do not reflect current environmental exposure conditions of MP encountered by fish in the wild (Mizraji et al., 2017; Nelms et al., 2018). Instead, these results must be viewed as a proof of concept to understand the underlying mechanisms through with MP exposure can negatively affect fish. Further research with environmentally realistic exposure conditions should therefore be tested, with focus on the direct (i.e. $\mathrm{Zn}$ assimilation, liver and brain metabolomics, hepatic vacuolation) and qualitative effects (i.e., apparent increased aggression, altered gut microbiome) observed in this study.

To conclude, this study highlights the benefits of looking over a variety of biological endpoints within the same experimental framework to better assess the effects of MP on fish. With observed effects of MP ingestion on fish survival, $\mathrm{Zn}$ assimilation, intestine and liver histopathology as well as brain and liver primary metabolite profiles, this study would benefit from further research examining the relationship between these defects and microbiome and behavioral impairments, to better understand the potentially causal and consequential mechanisms of MP toxicity on fish.

\section{Acknowledgements}

The work was supported by funds from the International Atomic Energy Agency (IAEA; Peaceful use initiative), by USR 3278 CNRS-EPHE UPVD (Contrat de Projet Etat-Polynésie française 2015-2020, LabEx Corail - project Etape, PSL environment - project Pesticor, Agence de l'eau - Rhone Méditérranée Corse - Grant No. 2018 1765). HJ and MB were affiliated to IAEA-EL during the time of the experiments and the subsequent works. The authors are grateful to G. Guillou from the Plateforme Analyses Isotopiques of the LIENSs laboratory for running stable isotope analysis. We are grateful to the Contrat de Projet EtatRégion (CPER) and the Fonds Européen de Développement Régional (FEDER) for funding the isotope-ratio mass spectrometers of LIENSs laboratory. The IUF (Institut Universitaire de France) is acknowledged for their support to PB as a Senior Member. The IAEA is grateful for the support provided to its Environment Laboratories by the Government of the Principality of 
Monaco. We thank Pascale Roux and Laetitia Lèbre (IGFL's sequencing platform) for their help with the metagenomics experiment.

\section{References}

Alomar, C., Sanz-Martín, M., Compa, M., Rios-Fuster, B., Álvarez, E., Ripoles, V., Valencia, J.M., Deudero S., 2021. Microplastic ingestion in reared aquaculture fish: Biological responses to low-density polyethylene controlled diets in Sparus aurata. Environ. Pollut. 280, 116960. https://doi.org/10.1016/j.envpol.2021.116960

Avio, C.G., Gorbi, S., Regoli, F., 2017. Plastics and microplastics in the oceans: From emerging pollutants to emerged threat. Mar. Environ. Res. 128, 2-11. https://doi.org/10.1016/j.marenvres.2016.05.012

Barboza, L.G.A., Vieira, L.R., Branco, V., Carvalho, C., Guilhermino, L., 2018a. Microplastics increase mercury bioconcentration in gills and bioaccumulation in the liver, and cause oxidative stress and damage in Dicentrarchus labrax juveniles. Sci. Rep. 8, 15655. https://doi.org/10.1038/s41598-018-34125-z

Barboza, L.G.A., Vieira, L.R., Branco, V., Figueiredo, N., Carvalho, F., Carvalho, C., Guilhermino, L., 2018b. Microplastics cause neurotoxicity, oxidative damage and energy-related changes and interact with the bioaccumulation of mercury in the European seabass, Dicentrarchus labrax (Linnaeus, 1758). Aquat. Toxicol. 195, 49-57. https://doi.org/10.1016/j.aquatox.2017.12.008

Barboza, L.G.A., Vieira, L.R., Guilhermino, L., 2018c. Single and combined effects of microplastics and mercury on juveniles of the European seabass (Dicentrarchus labrax): Changes in behavioural responses and reduction of swimming velocity and resistance time. Environ. Pollut. 236, 1014-1019. https://doi.org/10.1016/j.envpol.2017.12.082

Belivermiş, M., Swarzenski, P., Oberhaensli, F., Melvin, S.D., Metian, M., 2020. Effects of variable deoxygenation on trace element bioaccumulation and resulting metabolome profiles in the blue mussel (Mytilus edulis). Chemosphere 126314.

https://doi.org/10.1016/j.chemosphere.2020.126314

Bergmann, M., Wirzberger, V., Krumpen, T., Lorenz, C., Primpke, S., Tekman, M.B., Gerdts, G., 2017. High Quantities of Microplastic in Arctic Deep-Sea Sediments from the HAUSGARTEN Observatory. Environ. Sci. Technol. 51, 11000-11010. https://doi.org/10.1021/acs.est.7b03331

Bligh, E.G., Dyer, W.J., 1959. A rapid method of total lipid extraction and purification. Can. 
J. Biochem. Physiol. 37, 911-917.

Chae, Y., An, Y.J., 2017. Effects of micro- and nanoplastics on aquatic ecosystems: Current research trends and perspectives. Mar. Pollut. Bull. 124, 624-632. https://doi.org/10.1016/j.marpolbul.2017.01.070

Chiba, S., Saito, H., Fletcher, R., Yogi, T., Kayo, M., Miyagi, S., Ogido, M., Fujikura, K., 2018. Human footprint in the abyss: 30 year records of deep-sea plastic debris. Mar. Policy 96, 204-212. https://doi.org/10.1016/j.marpol.2018.03.022

Choi, J.S., Jung, Y.J., Hong, N.H., Hong, S.H., Park, J.W., 2018. Toxicological effects of irregularly shaped and spherical microplastics in a marine teleost, the sheepshead minnow (Cyprinodon variegatus). Mar. Pollut. Bull. 129, 231-240. https://doi.org/10.1016/j.marpolbul.2018.02.039

Chouvelon, T., Spitz, J., Cherel, Y., Caurant, F., Sirmel, R., Mèndez-Fernandez, P., Bustamante, P., 2011. Inter-specific and ontogenic differences in $\delta 13 \mathrm{C}$ and $\delta 15 \mathrm{~N}$ values and $\mathrm{Hg}$ and Cd concentrations in cephalopods. Mar. Ecol. Prog. Ser. 433, 107120. https://doi.org/10.3354/meps09159

Clemente, J.C., Ursell, L.K., Parfrey, L.W., Knight, R., 2012. The impact of the gut microbiota on human health: An integrative view. Cell 148, 1258-1270. https://doi.org/10.1016/j.cell.2012.01.035

Cresswell, T., Metian, M., Golding, L.A., Wood, M.D., 2017. Aquatic live animal radiotracing studies for ecotoxicological applications: Addressing fundamental methodological deficiencies. J. Environ. Radioact. 178-179, 453-460. https://doi.org/10.1016/j.jenvrad.2017.05.017

de Sá, L.C., Oliveira, M., Ribeiro, F., Rocha, T.L., Futter, M.N., 2018. Studies of the effects of microplastics on aquatic organisms: What do we know and where should we focus our efforts in the future? Sci. Total Environ. 645, 1029-1039. https://doi.org/10.1016/j.scitotenv.2018.07.207

Egbeocha, C.O., Malek, S., Emenike, C.U., Milow, P., 2018. Feasting on microplastics: Ingestion by and effects on marine organisms. Aquat. Biol. 27, 93-106. https://doi.org/10.3354/ab00701

Eriksen, M., Lebreton, L.C.M., Carson, H.S., Thiel, M., Moore, C.J., Borerro, J.C., Galgani, F., Ryan, P.G., Reisser, J., 2014. Plastic pollution in the World's oceans: more than 5 trillion plastic pieces weighing over 250,000 tons afloat at sea. PLoS One 9, 1-15. https://doi.org/10.1371/journal.pone.0111913

Espinosa, C., Cuesta, A., Esteban, M.Á., 2017. Effects of dietary polyvinylchloride 
microparticles on general health, immune status and expression of several genes related to stress in gilthead seabream (Sparus aurata L.). Fish Shellfish Immunol. 68, 251-259. https://doi.org/10.1016/j.fsi.2017.07.006

Fackelmann, G., Sommer, S., 2019. Microplastics and the gut microbiome: How chronically exposed species may suffer from gut dysbiosis. Mar. Pollut. Bull. 143, 193-203. https://doi.org/10.1016/j.marpolbul.2019.04.030

Filosa, S., Di Meo, F., Crispi, S., 2018. Polyphenols-gut microbiota interplay and brain neuromodulation. Neural Regen. Res. 13, 2055.

Foley, C.J., Feiner, Z.S., Malinich, T.D., Höök, T.O., 2018. A meta-analysis of the effects of exposure to microplastics on fish and aquatic invertebrates. Sci. Total Environ. 631-632, 550-559. https://doi.org/10.1016/j.scitotenv.2018.03.046

Franzellitti, S., Canesi, L., Auguste, M., Wathsala, R.H.G.R., Fabbri, E., 2019. Microplastic exposure and effects in aquatic organisms: A physiological perspective. Environ.

Toxicol. Pharmacol. 68, 37-51. https://doi.org/10.1016/j.etap.2019.03.009

Guthrie, G.J., Aydemir, T.B., Troche, C., Martin, A.B., Chang, S.M., Cousins, R.J., 2015. Influence of ZIP14 (slc39A14) on intestinal zinc processing and barrier function. Am. J. Physiol. - Gastrointest. Liver Physiol. 308, G171-G178. https://doi.org/10.1152/ajpgi.00021.2014

Hinton, D.E., Segner, H., Braunbeck, T., 2017. Toxic responses of the liver, in: Target Organ Toxicity in Marine and Freshwater Teleosts. CRC Press, pp. 224-268.

Hogstrand, C., Wood, C.M., 2010. The physiology and toxicology of zinc in fish, in: Toxicology of Aquatic Pollution. Cambridge University Press, pp. 61-84. https://doi.org/10.1017/cbo9780511735516.005

Jabeen, K., Li, B., Chen, Q., Su, L., Wu, C., Hollert, H., Shi, H., 2018. Effects of virgin microplastics on goldfish (Carassius auratus). Chemosphere 213, 323-332. https://doi.org/10.1016/j.chemosphere.2018.09.031

Jabeen, K., Su, L., Li, J., Yang, D., Tong, C., Mu, J., Shi, H., 2017. Microplastics and mesoplastics in fish from coastal and fresh waters of China. Environ. Pollut. 221, 141149.

Jacob, H., Besson, M., Swarzenski, P.W., Lecchini, D., Metian, M., 2020. Effects of virgin micro- and nanoplastics on fish: Trends, meta-analysis, and perspectives. Environ. Sci. Technol. 54, 4733-4745. https://doi.org/10.1021/acs.est.9b05995

Jacob, H., Pouil, S., Lecchini, D., Oberhänsli, F., Swarzenski, P., Metian, M., 2017. Trophic transfer of essential elements in the clownfish Amphiprion ocellaris in the context of 
ocean acidification. PLoS One. https://doi.org/10.1371/journal.pone.0174344

Jambeck, J.R., Geyer, R., Wilcox, C., Siegler, T.R., Perryman, M., Andrady, A., Narayan, R., Law, K.L., 2015. Plastic waste inputs from land into the ocean. Science 347 (6223), 768-771. https://doi.org/10.1126/science.1260352

Jin, Y., Xia, J., Pan, Z., Yang, J., Wang, W., Fu, Z., 2018. Polystyrene microplastics induce microbiota dysbiosis and inflammation in the gut of adult zebrafish. Environ. Pollut. 235, 322-329. https://doi.org/10.1016/j.envpol.2017.12.088

Jovanović, B., Gökdağ, K., Güven, O., Emre, Y., Whitley, E.M., Kideys, A.E., 2018. Virgin microplastics are not causing imminent harm to fish after dietary exposure. Mar. Pollut. Bull. 130, 123-131. https://doi.org/10.1016/j.marpolbul.2018.03.016

Karami, A., Romano, N., Galloway, T., Hamzah, H., 2016. Virgin microplastics cause toxicity and modulate the impacts of phenanthrene on biomarker responses in African catfish (Clarias gariepinus). Environ. Res. 151, 58-70. https://doi.org/10.1016/j.envres.2016.07.024

Kormas, K.A., Meziti, A., Mente, E., Frentzos, A., 2014. Dietary differences are reflected on the gut prokaryotic community structure of wild and commercially reared sea bream (Sparus aurata). Microbiologyopen 3, 718-728. https://doi.org/10.1002/mbo3.202

Lei, L., Wu, S., Lu, S., Liu, M., Song, Y., Fu, Z., Shi, H., Raley-Susman, K.M., He, D., 2018. Microplastic particles cause intestinal damage and other adverse effects in zebrafish Danio rerio and nematode Caenorhabditis elegans. Sci. Total Environ. 619-620, 1-8. https://doi.org/10.1016/j.scitotenv.2017.11.103

LeMoine, C.M.R., Kelleher, B.M., Lagarde, R., Northam, C., Elebute, O.O., Cassone, B.J., 2018. Transcriptional effects of polyethylene microplastics ingestion in developing zebrafish (Danio rerio). Environ. Pollut. 243, 591-600. https://doi.org/10.1016/j.envpol.2018.08.084

Ling, S.D., Sinclair, M., Levi, C.J., Reeves, S.E., Edgar, G.J., 2017. Ubiquity of microplastics in coastal seafloor sediments. Mar. Pollut. Bull. 121, 104-110. https://doi.org/10.1016/j.marpolbul.2017.05.038

Lu, Y., Zhang, Y., Deng, Y., Jiang, W., Zhao, Y., Geng, J., Ding, L., Ren, H., 2016. Uptake and Accumulation of Polystyrene Microplastics in Zebrafish (Danio rerio) and Toxic Effects in Liver. Environ. Sci. Technol. 50, 4054-4060. https://doi.org/10.1021/acs.est.6b00183

Luís, L.G., Ferreira, P., Fonte, E., Oliveira, M., Guilhermino, L., 2015. Does the presence of microplastics influence the acute toxicity of chromium(VI) to early juveniles of the 
common goby (Pomatoschistus microps)? A study with juveniles from two wild estuarine populations. Aquat. Toxicol. 164, 163-174. https://doi.org/10.1016/j.aquatox.2015.04.018

Lusher, A.L., Tirelli, V., O’Connor, I., Officer, R., 2015. Microplastics in Arctic polar waters: The first reported values of particles in surface and sub-surface samples. Sci. Rep. 5, 14947. https://doi.org/10.1038/srep14947

Martin, C.R., Osadchiy, V., Kalani, A., Mayer, E.A., 2018. The brain-gut-microbiome axis. Cell. Mol. Gastroenterol. Hepatol. 6, 133-148.

Martins, C.I.M., Galhardo, L., Noble, C., Damsgård, B., Spedicato, M.T., Zupa, W., Beauchaud, M., Kulczykowska, E., Massabuau, J.C., Carter, T., Planellas, S.R., Kristiansen, T., 2012. Behavioural indicators of welfare in farmed fish. Fish Physiol. Biochem. 38, 17-41. https://doi.org/10.1007/s10695-011-9518-8

Mattsson, K., Ekvall, M.T., Hansson, L.A., Linse, S., Malmendal, A., Cedervall, T., 2015. Altered behavior, physiology, and metabolism in fish exposed to polystyrene nanoparticles. Environ. Sci. Technol. 49, 553-561. https://doi.org/10.1021/es5053655

Mazurais, D., Ernande, B., Quazuguel, P., Severe, A., Huelvan, C., Madec, L., Mouchel, O., Soudant, P., Robbens, J., Huvet, A., Zambonino-Infante, J., 2015. Evaluation of the impact of polyethylene microbeads ingestion in European sea bass (Dicentrarchus labrax) larvae. Mar. Environ. Res. 112, 78-85. https://doi.org/10.1016/j.marenvres.2015.09.009

McCauley, S.J., Bjorndal, K.A., 1999. Conservation implications of dietary dilution from debris ingestion: Sublethal effects in post-hatchling loggerhead sea turtles. Conserv. Biol. 13, 925-929. https://doi.org/10.1046/j.1523-1739.1999.98264.x

Melvin, S.D., Habener, L.J., Leusch, F.D.L., Carroll, A.R., 2017. 1H NMR-based metabolomics reveals sub-lethal toxicity of a mixture of diabetic and lipid-regulating pharmaceuticals on amphibian larvae. Aquat. Toxicol. 184, 123-132. https://doi.org/10.1016/j.aquatox.2017.01.012

Melvin, S.D., Jones, O.A.H., Carroll, A.R., Leusch, F.D.L., 2018. 1H NMR-based metabolomics reveals interactive effects between the carrier solvent methanol and a pharmaceutical mixture in an amphibian developmental bioassay with Limnodynastes peronii. Chemosphere 199, 372-381. https://doi.org/10.1016/j.chemosphere.2018.02.063

Metian, M., Bustamante, P., Hédouin, L., Oberhänsli, F., Warnau, M., 2009. Delineation of heavy metal uptake pathways (seawater and food) in the variegated scallop Chlamys varia, using radiotracer techniques. Mar. Ecol. Prog. Ser. 375, 161-171. 
https://doi.org/10.3354/meps07766

Mizraji, R., Ahrendt, C., Perez-venegas, D., Vargas, J., Pulgar, J., Aldana, M., Ojeda, F.P., Duarte, C., Galbán-malagón, C., 2017. Is the feeding type related with the content of microplastics in intertidal fish gut? Mar. Pollut. Bull. 116, 498-500 https://doi.org/10.1016/j.marpolbul.2017.01.008

Moore, C.J., 2008. Synthetic polymers in the marine environment: A rapidly increasing, longterm threat. Environ. Res. 108, 131-139. https://doi.org/10.1016/j.envres.2008.07.025

Mu, J., Jin, F., Wang, J., Zheng, N., Cong, Y., 2015. Effects of $\mathrm{CO}_{2}$-driven ocean acidification on early life stages of marine medaka (Oryzias melastigma). Biogeosciences Discuss. 12, 1-20. https://doi.org/10.5194/bgd-12-1-2015

Nelms, S.E., Galloway, T.S., Godley, B.J., Jarvis, D.S., Lindeque, P.K., 2018. Investigating microplastic trophic transfer in marine top predators. Environ. Pollut. 238, 999-1007. https://doi.org/10.1016/j.envpol.2018.02.016

Oliveira, M., Ribeiro, A., Hylland, K., Guilhermino, L., 2013. Single and combined effects of microplastics and pyrene on juveniles (0+ group) of the common goby Pomatoschistus microps (Teleostei, Gobiidae). Ecol. Indic. 34, 641-647. https://doi.org/10.1016/j.ecolind.2013.06.019

Pedà, C., Caccamo, L., Fossi, M.C., Gai, F., Andaloro, F., Genovese, L., Perdichizzi, A., Romeo, T., Maricchiolo, G., 2016. Intestinal alterations in European sea bass Dicentrarchus labrax (Linnaeus, 1758) exposed to microplastics: preliminary results. Environ. Pollut. 212, 251-256. https://doi.org/10.1016/j.envpol.2016.01.083

Pouil, S., Bustamante, P., Warnau, M., Metian, M., 2018a. Overview of trace element trophic transfer in fish through the concept of assimilation efficiency. Mar. Ecol. Prog. Ser. 588, 243-254. https://doi.org/10.3354/meps 12452

Pouil, S., Oberhänsli, F., Bustamante, P., Metian, M., 2018b. Investigations of temperature and $\mathrm{pH}$ variations on metal trophic transfer in turbot (Scophthalmus maximus). Environ. Sci. Pollut. Res. 25, 11219-11225. https://doi.org/10.1007/s11356-017-8691-4

Qiao, R., Sheng, C., Lu, Y., Zhang, Y., Ren, H., Lemos, B., 2019. Microplastics induce intestinal inflammation, oxidative stress, and disorders of metabolome and microbiome in zebrafish. Sci. Total Environ. 662, 246-253. https://doi.org/10.1016/j.scitotenv.2019.01.245

Quereda, J.J., Dussurget, O., Nahori, M.A., Ghozlane, A., Volant, S., Dillies, M.A., Regnault, B., Kennedy, S., Mondot, S., Villoing, B., Cossart, P., Pizarro-Cerda, J., 2016. Bacteriocin from epidemic Listeria strains alters the host intestinal microbiota to favor 
infection. Proc. Natl. Acad. Sci. U. S. A. 113, 5706-5711.

https://doi.org/10.1073/pnas.1523899113

Rist, S., Baun, A., Hartmann, N.B., 2017. Ingestion of micro- and nanoplastics in Daphnia magna - Quantification of body burdens and assessment of feeding rates and reproduction. Environ. Pollut. 228, 398-407. https://doi.org/10.1016/j.envpol.2017.05.048

Rochman, C.M., 2018. Microplastics research-from sink to source. Science 360 (6384), 2829. https://doi.org/10.1126/science.aar7734

Romano, N., Ashikin, M., Teh, J.C., Syukri, F., Karami, A., 2018. Effects of pristine polyvinyl chloride fragments on whole body histology and protease activity in silver barb Barbodes gonionotus fry. Environ. Pollut. 237, 1106-1111. https://doi.org/10.1016/j.envpol.2017.11.040

Saunders, S.R., Hoppa, R.D., 1993. Growth deficit in survivors and non-survivors: Biological mortality bias in subadult skeletal samples. Am. J. Phys. Anthropol. 36, 127-151. https://doi.org/10.1002/ajpa.1330360608

Setälä, O., Lehtiniemi, M., Coppock, R., Cole, M., 2018. Microplastics in marine food webs, in: Microplastic Contamination in Aquatic Environments. Elsevier, pp. 339-363. https://doi.org/10.1016/b978-0-12-813747-5.00011-4

Spencer, M.D., Hamp, T.J., Reid, R.W., Fischer, L.M., Zeisel, S.H., Fodor, A.A., 2011. Association between composition of the human gastrointestinal microbiome and development of fatty liver with choline deficiency. Gastroenterology 140, 976-986. https://doi.org/10.1053/j.gastro.2010.11.049

Sullam, K.E., Essinger, S.D., Lozupone, C.A., O’Connor, M.P., Rosen, G.L., Knight, R., Kilham, S.S., Russell, J.A., 2012. Environmental and ecological factors that shape the gut bacterial communities of fish: A meta-analysis. Mol. Ecol. 21, 3363-3378. https://doi.org/10.1111/j.1365-294X.2012.05552.x

Tang, B.L., 2017. Commentary: Tissue accumulation of microplastics in mice and biomarker responses suggest widespread health risks of exposure. Front. Environ. Sci. 5, 63.

Ter Halle, A., Ladirat, L., Gendre, X., Goudouneche, D., Pusineri, C., Routaboul, C., Tenailleau, C., Duployer, B., Perez, E., 2016. Understanding the fragmentation pattern of marine plastic debris. Environ. Sci. Technol. 50, 5668-5675. https://doi.org/10.1021/acs.est.6b00594

Van der Oost, R., Beyer, J., Vermeulen, N.P.E., 2003. Fish bioaccumulation and biomarkers in environmental risk assessment: A review. Environ. Toxicol. Pharmacol. 13, 57-149. 
https://doi.org/10.1016/S1382-6689(02)00126-6

Varó, I., Osorio, K., Estensoro, I., Naya-Català, F., Sitjà-Bobadilla, A., Navarro, J.-C., PérezSánchez, J., Torreblanca, A., Piazzon, C.M., 2021. Effect of virgin low density polyethylene microplastic ingestion on intestinal histopathology and microbiota of gilthead sea bream. Aquaculture 545: 737245 https://doi.org/10.1016/j.aquaculture.2021.737245

Verona, E., Kilmer, A., 2007. Stress exposure and affective modulation of aggressive behavior in men and women. J. Abnorm. Psychol. 116, 410-421. https://doi.org/10.1037/0021-843X.116.2.410

Wan, Z., Wang, C., Zhou, J., Shen, M., Wang, X., Fu, Z., Jin, Y., 2019. Effects of polystyrene microplastics on the composition of the microbiome and metabolism in larval zebrafish. Chemosphere 217, 646-658. https://doi.org/10.1016/j.chemosphere.2018.11.070

Welden, N.A.C., Cowie, P.R., 2016. Long-term microplastic retention causes reduced body condition in the langoustine, Nephrops norvegicus. Environ. Pollut. 218, 895-900. https://doi.org/10.1016/j.envpol.2016.08.020

Wolf, J.C., Wheeler, J.R., 2018. A critical review of histopathological findings associated with endocrine and non-endocrine hepatic toxicity in fish models. Aquat. Toxicol. 197, 60-78. https://doi.org/10.1016/j.aquatox.2018.01.013

Wright, S.L., Thompson, R.C., Galloway, T.S., 2013. The physical impacts of microplastics on marine organisms: A review. Environ. Pollut. 178, 483-492.

Yamashiro, Y., 2018. Gut microbiota in health and disease. Ann. Nutr. Metab. 71, 242-246. https://doi.org/10.1159/000481627

Yarandi, S.S., Peterson, D.A., Treisman, G.J., Moran, T.H., Pasricha, P.J., 2016. Modulatory effects of gut microbiota on the central nervous system: How gut could play a role in neuropsychiatric health and diseases. J. Neurogastroenterol. Motil. 22, 201.

Yin, L., Chen, B., Xia, B., Shi, X., Qu, K., 2018. Polystyrene microplastics alter the behavior, energy reserve and nutritional composition of marine jacopever (Sebastes schlegelii). J. Hazard. Mater. 360, 97-105. https://doi.org/10.1016/j.jhazmat.2018.07.110 